\title{
Peri-partum cardiomayopathy-not a rare entity, clinical profile in a rural tertiary care center in Gujarat, India
}

\author{
Rumi Bhattacharjee*, Nitin Raithata, Molina Patel, Smruti Vaishnav
}

Department of Obstetrics and Gynecology, Pramukh Swami Medical College, Karamsad, Gujarat, India

Received: 12 February 2017

Accepted: 07 March 2017

\section{*Correspondence:}

Dr. Rumi Bhattacharjee,

E-mail: rumigynae@gmail.com

Copyright: (c) the author(s), publisher and licensee Medip Academy. This is an open-access article distributed under the terms of the Creative Commons Attribution Non-Commercial License, which permits unrestricted non-commercial use, distribution, and reproduction in any medium, provided the original work is properly cited.

\begin{abstract}
Background: Peri-partum cardiomayopathy (PPCM) in pregnancy has a potential to adversely affect both mother and fetus. Severe cases can be associated with life threatening complications unless managed promptly by multidisciplinary team. The objective was to study maternal and fetal outcome of PPCM patients.

Methods: An observational cohort over 4 years (2012 to 2015) was conducted in a Rural tertiary care center. Consecutive antenatal and postpartum women with PPCM were studied for medical and obstetric complications, deliveries, fetal outcome and maternal mortality.

Results: The incidence of PPCM was $0.3 \%$ and Most patients presented with typical signs and symptoms of heart failure. 55.5\% were in NYHA 3 and 4 and 50\% had ejection fraction below 30\%. 83.3\% required ICU admissions of varying length and Maternal mortality was in 1 patient (5.56\%). PPCM occurred in 55.5\% of ante partum against $44.4 \%$ of postpartum patients. Obstetric complications like PPH occurred in $11.1 \%$ while poor fetal outcome like preterm deliveries occurred in 50\% while still births in $16.67 \%$.

Conclusions: The low incidence and rarity of PPCM presents itself with diagnostic dilemma. Obstetrician should have high index of suspicion in patients with heart failure and high risk factors. Early diagnosis and prompt treatment can only improve the outcome.
\end{abstract}

Keywords: Cardiomyopathy distress, Peri-partum cardiomayopathy

\section{INTRODUCTION}

Peri partum Cardiomayopathy (PPCM) is a rare potentially life-threatening cardiac disease occurring in the last month and within 5 months of delivery in previously healthy women. The diagnostic criteria include an echocardiography finding of ejection fraction of less than $45 \%$, fractional shortening of less than $30 \%$ and diastolic dimension of greater than $2.7 \mathrm{~cm} / \mathrm{m} 2$ body surface area. ${ }^{1}$ The incidence is reported to be 1 in 3000 to 1 in 400 live birth. $^{2}$ The etiology is unknown, though some risk factors are cited such as advanced maternal age, multiparity, multiple gestations, pre-eclampsia, chronic hypertension etc. ${ }^{3-5}$ The signs and symptoms are subtle and pathogenesis is poorly understood. PPCM may remain unrecognized and the diagnosis is by exclusion of other heart diseases, sepsis, pulmonary embolism, valvular disease, idiopathic dilated cardiomyopathy and MI. This rare and fatal disease has a mortality rate of 30$60 \%$ and recurrence of $50-80 \%$ with uncommon complications such as pulmonary congestion and thromboembolic events. ${ }^{1}$ A multidisciplinary approach is required to manage the heart failure during pregnancy and provide optimum outcome. This study was done with the objectives to find out incidence of PPCM among cardiovascular disease in pregnancy and to study the spectrum of PPCM along with maternal and fetal outcome in pregnancy with PPCM. 


\section{METHODS}

It is a retrospective observational database analysis conducted in the department of obstetrics and gynecology in SKH over a period of 4 years from Jan 2012 to Dec 2015. Data was collected from medical record department after ethics committee approval. Consecutive data of all pregnant women and postpartum women with PPCM were systematically studied. As it is retrospective study waiver of informed consent was sought from ethics committee. Diagnosis was based on suspicious clinical findings of heart failure such as tachycardia, dyspnoea, chest pain, pedal edema, raised JVP, PND, haemoptysis, nocturnal cough, anasarca, wet crepitations on lung fields, systolic murmur, PIH, new onset MI, hepatospleenomegaly, low spo2 etc. Diagnosis was supplemented with ECG and chest $\mathrm{x}$-ray findings. Echocardiography findings of ejection fraction $<45 \%$ confirmed the diagnosis of PPCM. All patients were hospitalized during the acute phase. Detailed history was taken of each patient and thorough clinical and obstetrical examination was done. NST, USG and Doppler was done where required to assess the fetal well-being. Management was done in collaboration with intensivist and cardiologist. They were given standard care for heart failure and were managed in ICU. Patients were monitored for signs and complication of thromboembolism, DIC, cardiac arrhythmia, systemic and pulmonary embolism, renal and liver failure. Fluid and salt restriction, digoxin, diuretic vasodilators and anticoagulants were instituted. They received parenteral nutrition, parenteral antibiotics and ventilator support as needed.
Obstetric complications were also looked for such as antepartum, intrapartum or postpartum haemorrhage, PROM, preterm delivery, IUFD. Patients with past history of PPCM were counseled regarding risk factors associated with continuing pregnancy.

Termination of pregnancy was done in patients with IUFD, severe IUGR, non-reactive NST, PROM and severe heart failure. LSCS was done for obstetric indications and in critically ill mothers. All women with manifestations of bleeding and deranged coagulation profile were infused with fresh frozen plasma and packed red blood cells. Per rectal misoprostol (400 micro gram) was kept and/or concentrated oxytocin drip was started to prevent PPH after delivery. Patients who improved clinically or showed signs of improvement on echocardiography were discharged and followed up in OPD variables.

\section{RESULTS}

The incidence of cardiovascular diseases in this study group during a period of 4 years was $1.1 \%$. PPCM constituted to $0.3 \%$ of total obstetric admissions during the study. Table 1 shows patient characteristics. Most of the people in our study were in the age group of 21-23 years. Out of 18 patients 13 were second gravida. 1 patient was grand multipara. 4 patients had multiple pregnancy. Most of the patients belonged to low socioeconomic status. 10 out of 18 patients presented in their antepartum period. 8 patients were postpartum.

Table 1: Patient characteristics.

\begin{tabular}{|llllllllllll|}
\hline Age & $\mathbf{N}$ & $\%$ & Parity & $\mathbf{N}$ & $\%$ & No. of fetus & N & $\%$ & Socio economic status & N & $\%$ \\
\hline $18-20$ & 3 & 16.67 & 0 & 1 & 5.5 & Single & 14 & 77.7 & low & 10 & 55.5 \\
\hline $21-23$ & 6 & 33.33 & 1 & 13 & 72.2 & Twins & 4 & 22.2 & Middle & 6 & 33.3 \\
\hline $24-26$ & 3 & 16.67 & 2 & 3 & 16.6 & Triplets & 0 & 0 & High & 2 & 11.1 \\
\hline $27-29$ & 3 & 16.67 & 3 & 0 & 0 & & & & & \\
\hline $30-34$ & 2 & 11.11 & $>3$ & 1 & 5.5 & & & & & \\
\hline$>35$ & 1 & 5.56 & & & & & & & & \\
\hline Total & $\mathbf{1 8}$ & & & $\mathbf{1 8}$ & & $\mathbf{1 8}$ & & \\
\hline
\end{tabular}

Table 2 shows the mean lab values at admission and at discharge. A decreasing trend is seen in most of the parameters.

Table 3 shows the presenting symptomatology of patients with PPCM, Tachycardia, PIH, Dyspnea, Wet lungs and Pedal edema was present in most of the patients. Very few patients in our study had orthopnea, MI or hepatospleenomegaly

$55.5 \%$ patients were in NYHA 3 and 4, 44.4\% patients were in NYHA grade 2. $50 \%$ patients had an ejection fraction between $\{30-45\} \%$ in their echocardiographic finding, and 38.88 had ejection fraction between $20-30 \%$.

Table 6 shows wide spectrum of maternal complications ranging from febrile illness to mortality. $56.6 \%$ patients had fever, $38.39 \%$ patients had eclampsia and $22.2 \%$ patients had developed coagulation defects. $5.56 \%$ patients had bleeding from different sites. $83.3 \%$ patients required ICU admission. The maximum ICU stay was 6 days for 1 patient while the average ICU stay was 2-4 days. 10 patients needed to be transfused blood and blood products. 2 patients developed cerebral emboli while 1 patient developed arterial emboli. $66.67 \%$ patients had 
compromised heart function. $50 \%$ patients required ventilator support ranging from few hours to few days. Maternal mortality occurred in 1 patient who was a second gravida at 18 weeks' gestation with absent FHS. She had PPCM in previous pregnancy also. She presented with bilateral pulmonary edema and ejection fraction of $20 \%$ and global hypokinesia. Cause of mortality was Congestive cardiac failure.

Table 2: Lab data and investigations.

\begin{tabular}{|lll|}
\hline Investigations & $\begin{array}{l}\text { On } \\
\text { admission }\end{array}$ & On discharge \\
\hline Mean $\mathrm{Hb}(\mathrm{gm} / \mathrm{l})$ & 10.1 & 10.65 \\
\hline $\begin{array}{l}\text { Mean count } \\
\text { (cells*100/l) }\end{array}$ & 17.1 & 19.6 \\
\hline $\begin{array}{l}\text { Mean platelets } \\
\text { (cells*1000/l) }\end{array}$ & 233 & 246 \\
\hline Mean S. Proteins & 4.76 & 3.6 \\
\hline Mean S. Urea & 42.5 & 45 \\
\hline Mean S. Creatinine & 0.88 & 0.9 \\
\hline Mean AST & 25 & 30 \\
\hline Mean ALT & 27.33 & 26 \\
\hline Mean S. Billirubin & $1.1 \mathrm{mg} \%$ & $1 \mathrm{mg} \%$ \\
\hline Mean INR & 1.5 & 1.09 \\
\hline Mean Na+ & 137.2 & 135 \\
\hline Mean K+ & 4.27 & 3.5 \\
\hline $\begin{array}{l}\text { Cardiomegaly } \\
\text { Pulmonary Edema }\end{array}$ & 8 & 4 \\
\hline $\begin{array}{l}\text { ECG changes } \\
\text { T wave inversion, ST } \\
\text { depression, multiple } \\
\text { atrial premature } \\
\text { beats, VPB }\end{array}$ & 6 & 0 \\
\hline
\end{tabular}

Table 3: Patient symptomatology.

\begin{tabular}{|lll|}
\hline Symptom/ Finding & No. & $\%$ \\
\hline Tachycardia & 13 & 72.22 \\
\hline Dyspnoea & 12 & 66.67 \\
\hline Orthopnoea & 0 & 0 \\
\hline Chest pain & 4 & 22.22 \\
\hline Pedal edema & 9 & 50 \\
\hline Raised JVP & 0 & 0 \\
\hline PND & 0 & 0 \\
\hline Nocturnal cough & 2 & 11.11 \\
\hline Anasarca & 4 & 22.22 \\
\hline Wet crepitations on lung & 10 & 55.56 \\
\hline Systolic murmur & 3 & 16.67 \\
\hline PIH & 13 & 72.22 \\
\hline Eclampsia & 7 & 38.89 \\
\hline Chronic Hypertension & 1 & 5.56 \\
\hline New onset MI & 1 & 5.56 \\
\hline Hepatospleenomegaly & 2 & 11.11 \\
\hline
\end{tabular}

Table 4: NYHA grade.

\begin{tabular}{|lll|}
\hline NYHA Grade & No. & $\%$ \\
\hline 1 & 0 & 0 \\
\hline 2 & 8 & 44.44 \\
\hline 3 & 6 & 33.33 \\
\hline 4 & 4 & 22.2 \\
\hline
\end{tabular}

Table 5: Echocardiography.

\begin{tabular}{|lllllll|} 
Ejection & $30-$ & & $20-$ & $\%$ & $<20$ & $\%$ \\
Fraction & $\mathbf{4 5}$ & $\%$ & $30 \%$ & $\%$ & $\%$ & \\
\hline patients & 9 & 50 & 7 & $\begin{array}{l}38.8 \\
8\end{array}$ & 2 & 11. \\
\hline
\end{tabular}

Table 6: Medical complications.

\begin{tabular}{|lll|}
\hline & No. & $\%$ \\
\hline Fever & 10 & 55.56 \\
\hline Ascites & 3 & 16.67 \\
\hline Pleural effusion & 2 & 11.11 \\
\hline Pericardial effusion & 1 & 5.56 \\
\hline Eclampsia & 7 & 38.89 \\
\hline Bleeding from different sites & 1 & 5.56 \\
\hline Deranged RFT & 1 & 5.56 \\
\hline Deranged LFT & 1 & 5.56 \\
\hline Deranged coagulation profile & 4 & 22.22 \\
\hline Cerebral emboli & 2 & 11.11 \\
\hline Arterial emboli & 1 & 5.56 \\
\hline Need for blood products & 10 & 55.5 \\
\hline ICU admission & 15 & 83.3 \\
\hline Compromised heart function & 12 & 66.67 \\
\hline $\begin{array}{l}\text { Patients requiring ventilatory } \\
\text { support }\end{array}$ & 9 & 50 \\
\hline Mortality & 1 & \\
\hline
\end{tabular}

Table 7 narrates the Obstetric outcome. Among the 18 patients, 10 were antepartum, out of which 1 had a second trimester abortion. 8 patients delivered outside. Total preterm deliveries (both vaginal and LSCS) were $6(33.33 \%), 16.67 \%$ had LSCS for obstetric or medical indications. 3 women had IUFD. 2 patients developed PPH which was managed conservatively. 2 of the women had conceived after developing PPCM in last pregnancy also. 2 women were discharged antenatal and they delivered live babies at or near term. All the patients were followed up in postnatal OPD after discharge and were healthy. However, 3 were lost to follow up.

The fetal outcome is presented in table 8. Both in-patient deliveries and outside deliveries were considered. 50\% were preterm babies and $16.6 \%$ were still births, $77.8 \%$ babies were born live out of which $66.6 \%$ had IUGR and $44.4 \%$ had birth weight $<2.5 \mathrm{~kg}$. $66.7 \%$ babies had APGAR $<7$ at 5 minutes. $66.6 \%$ babies required NICU admission. There was no neonatal death. 
Table 7: Obstetrics outcome.

\begin{tabular}{|lll|}
\hline Outcome & No. & $\%$ \\
\hline Abortion & 1 & 5.56 \\
\hline PROM & 0 & 0 \\
\hline Preterm deliveries (vaginal and CS) & 6 & 33.33 \\
\hline LSCS & 3 & 16.67 \\
\hline Instrumental delivery & 2 & 11.1 \\
\hline Foetal distress & 1 & 5.56 \\
\hline IUFD & 3 & 16.6 \\
\hline PPH & 2 & 11.11 \\
\hline Induction of labour & 1 & 5.56 \\
\hline $\begin{array}{l}\text { Continued pregnancy and delivered at } \\
\text { term }\end{array}$ & 2 & 11.11 \\
\hline Conceived after PPCM in last pregnancy & 2 & 11.11 \\
\hline Full term deliveries & 3 & 16.67 \\
\hline Lost to follow up & 3 & 16.66 \\
\hline
\end{tabular}

Table 8: Fetal outcome.

\begin{tabular}{|lll|}
\hline Outcome & No. & $\%$ \\
\hline Prematurity & 9 & 50 \\
\hline IUGR & 12 & 66.6 \\
\hline Birth weight $<2.5 \mathrm{~kg}$ & 8 & 44.4 \\
\hline APGAR $<7$ at $5 \mathrm{~min}$ & 12 & 66.7 \\
\hline NICU admission & 13 & 72.22 \\
\hline Still birth & 3 & 16.67 \\
\hline Live birth & 14 & 77.8 \\
\hline NND & 0 & 0 \\
\hline Total perinatal deaths & 3 & 16.67 \\
\hline
\end{tabular}

\section{DISCUSSION}

Descriptions of peripartum cardiomyopathy can be dated back to the $19^{\text {th }}$ century. The association of the heart failure and puerperium was first established by Ritchie in $1849 .{ }^{6}$ However it was only after 1937 , that PPCM was recognized as a distinctive form of cardiomyopathy. In the initial years, the condition was defined by several names such as postpartum failure, postpartum myocarditis, Meadows syndrome; Zaria syndrome etc. ${ }^{7}$ Demakis et al defined the condition Peripartum cardiomyopathy in 1971, when he described the spectrum of the disease in 27 pregnant women with cardiomegaly and congestive heart failure. He also gave the classical diagnostic criteria for PPCM, which was then modified by the National Heart Lung and Blood Institute and Office of Rare Disease. These criteria include: development of cardiac failure in last month of pregnancy or within 5 months after delivery, absence of demonstrable pre-existing cardiac disease, absence of an identifiable cause of heart failure, left ventricular systolic dysfunction demonstrated by classic echocardiographic criteria: ejection fraction $<45 \%$ or fractional shortening $<30 \%$ or both, and end diastolic dimension $>2.7 \mathrm{~cm} / \mathrm{m} 2$ body surface area. ${ }^{3-5}$
The incidence of PPCM is reported to be 1 in 1500 to 1:4000 live births. Mielniczuk et al reported an incidence of 1:3189 live births. 8 The prevalence is 1 case for 1,300 -15000 live births in USA; 1 case per 6000 live births in Japan, 1 case per 1000 live births in South Africa \& 1 case per $350-400$ live births in Haiti. ${ }^{2}$ The incidence is very high in Nigeria (1 in 100), while the incidence of PPCM in our study was 4 per 1000 deliveries. ${ }^{9}$ The incidence in another Indian study was 1 in 1374 live births. ${ }^{10}$

The pathogenesis of PPCM is controversial and many probable causes have been proposed. Advanced maternal age $>30$ has been associated with PPCM. ${ }^{3-5}$ However, such an association was not found in our study. Multiparity has also been implicated. $71 \%$ of cases were reported to occur $>3$ pregnancies as compared with $8 \%$ in primigravidas (Denatus, as cited in Ntusi). In our study, the incidence was found to be more in second and third gravidas. More incidence was found in multifetal pregnancies in some studies, which was not so in this study. The association of PPCM and gestational hypertension was found in $43 \% .^{3-5}$ In our study, the association was $38.8 \%$. In many studies, the incidence of PPCM was higher in post-partum patients than antepartum patients. In a study from China, $17 \%$ of cases were diagnosed antepartum and $83 \%$ were postpartum admissions. In our study, $55.5 \%$ were antepartum and $44.4 \%$ were postpartum.

The incidence is particularly high in some African countries, probably due to certain cultural practices followed during the puerperium. These include consuming lake salt or rock salt (Kanva) or heating of the body on a clay bed with fire beneath to keep warm. ${ }^{15}$

Recent studies implicate the role of a prolactin sub fragment $16 \mathrm{KDa}$ which is cleaved from prolactin due to unbalanced oxidative stress. The $16 \mathrm{KDa}$ can destroy the endothelium and damage the micro circulation in the myocardium, reducing the cardiac function and causing ventricular dilatation. ${ }^{12}$

Myocarditis has also been proposed as a cause of PPCM because of presence of fibrosis and necrosis in dilated hearts. Gouley et al, Melvin et al, Conoc, Ntusi and many others tried to show the association.

Abnormal immune response to pregnancy is another postulated theory, in which auto antibodies are formed after delivery against uterine degradation products such as actin and myosin. These antibodies then cross react with proteins in the myocardium and cause myotoxicity. Such antibodies have been reported in many studies and are associated with increased levels of tumor necrosis factor alpha, interleukin 6 etc. ${ }^{13,14}$

Another phenomenon is fetal chimerism in which fetal cells are present in maternal circulation during and after delivery, which after delivery are recognized by maternal 
system as foreign antigens and may trigger an immune response. ${ }^{13-15}$ Abnormal response to haemodynamic stress of pregnancy is a hypothesis which suggests that some alterations in the haemodynamic setup results in cardiac hypertrophy.

According to another theory, increased myocyte apoptosis may be a cause, wherein, there is an imbalance between cellular elimination and cellular regeneration due to over expression of certain genes. Recently the proapoptotic gene Nix or Bnip3 have been demonstrated to play an important role (Diwan, as cited in HilfikerKleiner)

Patients with PPCM present with classical symptoms of systolic heart failure. The most common symptoms are dyspnea and fatigue (90\%), tachycardia (62\%), peripheral edema (60\%). (Elkayam et al, Moioli et al, reported increased incidence of persistent nocturnal dry cough, orthopnea and paroxysmal nocturnal dyspnea. ${ }^{16}$ Tachycardia or supra ventricular tachyarrhythmias were reported by Bertrand. ${ }^{17}$

In our study, tachycardia (72.2\%), Dyspnea (66.6\%), chest pain $(22.2 \%)$ and pedal edema $(50 \%)$ were the main presenting symptoms.

Unusual presentations like acute cyanosis (cole et al), multiple thromboembolic events (Carlson et al), liver failure (Fussel et al), systemic and pulmonary embolic episodes (Bennani; Box; Jha) have also been described. ${ }^{18,19}$

The mainstay of investigations includes chest x-ray, ECG and echocardiography, besides an array of blood tests to detect hematological, renal and liver function abnormalities. Cardiac markers, such as Troponin $\mathrm{T}$ is suggested to have prognostic implication. B-type natriuretic peptide (BNP) and N terminal pro - BNP (NTpro BNP) are recommended by the Heart Failure Association of the ESC Working Group on PPCM. ${ }^{20}$

Antenatal testing such as non-stress test and serial ultrasonography should be done to monitor fetal wellbeing.

Management of PPCM is similar to that of heart failure. A multidisciplinary approach should be undertaken. Fluid and salt restriction, digoxin, vasodilators, diuretics and anticoagulants constitute the main line of treatment. Seriously ill patients are given supportive care in the ICU. The role of bromocriptine has also been studied by many. It can inhibit prolactin secretion and reduce activity of $16 \mathrm{kDa}$ proapoptotic form of prolactin. ${ }^{21,22}$

Mechanical Ventricular support and cardiac transplantation or intraaortic balloon pump counter pulsation may be needed in patients not responding to medical treatment. ${ }^{7}$
Patients who are hemodynamically stable can be allowed to go to term. However, for patients near term labour should be induced. Vaginal deliveries have many advantages such as minimal blood loss, greater hemodynamic stability, less surgical stress, and pulmonary complications. Effective pain management should be instituted. Second stage should be cut short with forceps or vacuum. Caesarean section should be reserved for obstetric indications or critically ill patients. ${ }^{1}$ A high caesarean section rate was reported by $\mathrm{H}$.V Gvordil et al. The c/s rate in our study was $16.67 \%$. Regional anaesthesia has benefits over general anaesthesia. Careful haemodynamic monitoring and fluid balance is obligatory. ${ }^{1}$

Obstetric and fetal outcome have not been extensively studied. Low birth weight, premature delivery, IUGR and fetal death have been reported by some authors. ${ }^{23} 50 \%$ of the babies born were preterm in our study. The incidence of still births was $16.67 \%$

PPCM may recur in subsequent pregnancies. Fett et al described a recurrence rate of $53 \%$. A study from Haiti reported $53.3 \%$ of recurrence in next pregnancies. ${ }^{24}$ In a study by Silva et al from South Africa, out of 6 women with recurrent PPCM, 2 died. Elkayan et al in the United States reported 44 women with PPCM in subsequent pregnancies. He recorded a high mortality rate $(19 \%)$ in patients who had ejection fraction less than $50 \%$ in the pre-pregnant state. In our study the recurrence rate was $11.1 \%$ out of which 1 patient had mortality.

According to Silva et al, pregnancy should be avoided if LV ejection fraction $<25 \%$ at diagnosis or with incompletely recovered left heart function. ${ }^{20}$ Contraceptive counseling is imperative. The combined oral contraceptives are contraindicated. Intrauterine systems or sterilization can be considered. ${ }^{20}$

\section{ACKNOWLEDGMENTS}

Author would like to thanks Dr. nachint and other residents for data compilation.

Funding: No funding sources Conflict of interest: None declared

Ethical approval: The study was approved by the Institutional Ethics Committee

\section{REFERENCES}

1. Lata I, Gupta R, Sahu S, Singh H.; Emergency management of decompensate peripartum cardiomyopathy. J Emerg Trauma Shock. 2009;2:124-8.

2. Demakis JG, Rahimtoola SH, Sutton GC, Meadws WR, Szanto PB, Tobin JR et al. Natural course of peripartum cardiomyopathy. Circulation. 1971;44:1053-61.

3. Demakis JG, Rahimtoola SH, Sutton GC, Meadows 
WR, Szanto PB, Tobin JR, Gunnar RM. Natural course of peripartum cardiomyopathy. Circulation. 1971;44(6):1053-61.

4. Fett JD, Christie LG. Unrecognized peripartum cardiomyopathy in Haitian women. Int $\mathbf{J}$ Gynaecol Obstet. 2005;90(2):161-6.

5. Fisher, S., Etherington, A. Peripartum cardiomyopathy: An update. Progr Ped Cardiol. 2008;25(1):79-84.

6. Ritchie, C. Clinical contribution to the pathology, diagnosis and treatment of certainchronic diseases in the heart. Edinburgh Med Surg. 1849;2:333.

7. Viviana Aursulesei and Mihai Dan Datcu Peripartum Cardiomyopathy: A Systematic Review University of Medicine and Pharmacy "Gr. T. Popa", Iasi Romania

8. Mielniczuk L.M. Frequency of peripartum cardiomyopathy. Am J Cardiol. 2006;97(12)17651768.

9. Sanderson JE, Adesanya CO, Anjorin FI et al. Postpartum cardiac failure-heart failure due to volume overload? Am Heart J. 1979;97:613-21.

10. Pandit V, Shetty S, Kumar A. Incidence and outcome of peripartum cardiomyopathy from a tertiary hospital in South India. Trop Doct. 2009;39(3):1689.

11. Murali, S, Baldisseri, MR. (2005). Peripartum cardiomyopathy. Crit Care Med. 2005;33(10):340-6,

12. Hilfiker-Kleiner D, Meyer GP, Schieffer E, Goldmann B, Podewski E, Struman I, Fischer P, Drexler H. Recovery from postpartum cardiomyopathy in 2 patients by blocking prolactin release with bromocriptine. Journal of the American College of Cardiology. 2007;50(24):2354-5.

13. Pearson GD, Veille JC, Rahimtoola S, Hsia J, Oakley CM, Hosenpud JD, Ansari A, Baughman KL. Peripartum cardiomyopathy: national heart, lung, and blood institute and office of rare diseases (national institutes of health) workshop recommendations and review. Jama. 2000;283(9):1183-8.

14. Sliwa K, Förster O, Libhaber E, Fett JD, Sundstrom JB, Hilfiker-Kleiner D, Ansari AA. Peripartum cardiomyopathy: inflammatory markers as predictors of outcome in 100 prospectively studied patients. European heart journal. 2006 ;27(4):441-6.

15. Ansari AA, Fett JD, Carraway RE, Mayne AE,
Onlamoon N, Sundstrom JB. Autoimmune mechanisms as the basis for human peripartum cardiomyopathy. Clinical reviews in allergy and immunology. 2002;23(3):301.

16. Elkayam U, Akhter MW, Singh H, Khan S, Bitar F, Hameed A, Shotan A. Pregnancy-associated cardiomyopathy. Circulation. 2005 Apr 26;111(16):2050-5.

17. Bertrand, E. La myocardiopathie du post-partum: à propos de cas. Arch Mal Coeur Vaiss. 1997;70(2):169-78.

18. Cole WC, Mehta JB, Roy TM, Downs CJ. Peripartum cardiomyopathy: echocardiogram to predict prognosis. Tennessee medicine: journal of the Tennessee Medical Association. 2001;94(4):135.

19. Bennani SL, Loubaris M, Lahlou I, Haddour N, Badidi M, Bouhouch R, Cherti M, Arharbi M. Postpartum cardiomyopathy revealed by acute lower limb ischemia. InAnnales de cardiologie et d'angeiologie 2003;52(6):382-85.

20. Sliwa, Karen, et al. "Current state of knowledge on aetiology, diagnosis, management, and therapy of peripartum cardiomyopathy: a position statement from the Heart Failure Association of the European Society of Cardiology Working Group on peripartum cardiomyopathy." European journal of heart failure. (2010):767-78.

21. Elkayam, U, Goland, S Bromocriptine for the treatment of peripartum cardiomyopathy. Circulation. 2010;121(13):1463-4,

22. Hilfiker-Kleiner D, Sliwa K, Drexler H. Peripartum cardiomyopathy: recent insights in its pathophysiology. Trends in cardiovascular medicine. 2008;18(5):173-9.

23. Veille JC. Peripartum cardiomyopathies: a review.Am J Obstet Gynecol. 1984;148:805-18.

24. Fett JD, Christie LG, Murphy JG. Brief communication: Outcomes of sub- sequent pregnancy after peripartum cardiomyopathy: a case series from Haiti. Ann Intern Med. 2006;145:30-4.

Cite this article as: BhattacharjeeR, Raithata N, Patel M, Vaishnav S. Peri-partum cardiomayopathy not a rare entity, clinical profile in a rural tertiary care center in Gujarat, India t. Int J Reprod Contracept Obstet Gynecol 2017;6:1544-9. 